(C) 2021, The Authors. Published by Elsevier Inc. and Fass Inc. on behalf of the American Dairy Science Association ${ }^{\circledR}$. This is an open access article under the CC BY-NC-ND license (http://creativecommons.org/licenses/by-nc-nd/4.0/).

\title{
Genetic parameters of semen quality traits and genetic correlations with service sire nonreturn rate in Nordic Holstein bulls
}

\author{
Grum Gebreyesus, ${ }^{1 *} \odot$ Mogens S. Lund, ${ }^{1}$ Kasia Kupisiewicz, ${ }^{2}$ and Guosheng Su${ }^{1}$ \\ ${ }^{1}$ Center for Quantitative Genetics and Genomics, Aarhus University, Blichers Allé 20, PO Box 50, DK-8830 Tjele, Denmark \\ ${ }^{2}$ Viking Genetics, Ebeltoftvej 16, DK-8960 Randers, Denmark
}

\section{ABSTRACT}

Despite the importance of the quality of semen used in artificial insemination to the reproductive success of dairy herds, few studies have estimated the extent of genetic variability in semen quality traits. Even fewer studies have quantified the correlation between semen quality traits and male fertility. In this study, records of 100,058 ejaculates collected from 2,885 Nordic Holstein bulls were used to estimate genetic parameters for semen quality traits, including pre- and postcryopreservation semen concentration, sperm motility and viability, ejaculate volume, and number of doses per ejaculate. Additionally, summary data on nonreturn rate (NRR) obtained from insemination of some of the bulls $(\mathrm{n}=$ 2,142 ) to cows in different parities (heifers and parities 1-3 or more) were used to estimate correlations between the semen quality traits and service sire NRR. In the study, low to moderate heritability (0.06-0.45) was estimated for semen quality traits, indicating the possibility of improving these traits through selective breeding. The study also showed moderate to high genetic and phenotypic correlations between service sire NRR and some of the semen quality traits, including sperm viability pre- and postcryopreservation, motility postcryopreservation, and sperm concentration precryopreservation, indicating the predictive values of these traits for service sire NRR. The positive moderate to high genetic correlations between semen quality and service sire NRR traits also indicated that selection for semen quality traits might be favorable for improving service sire NRR.

Key words: genetic correlation, heritability, male fertility, semen quality

\section{INTRODUCTION}

Reproductive performance is of paramount economic importance in the livestock industry, including dairy

\footnotetext{
Received March 4, 2021.

Accepted April 28, 2021.

*Corresponding author: grum.gebreyesus@qgg.au.dk
}

cattle production. Several studies in dairy and beef cattle have explored the genetic parameters of female fertility (Berry et al., 2019), but few have investigated the genetics of service sire fertility and its association with semen characteristics. Low semen quality and quantity have been shown to contribute to a significant percentage of reproductive failures in AI dairy cattle (DeJarnette et al., 2004). Additionally, studies have shown moderate to strong phenotypic associations between some semen quality traits and nonreturn rate (NRR) for bulls (Christensen et al., 2011; Morrell et al., 2018). Therefore, selective breeding to improve semen quality traits has the potential to increase conception rate, thereby lowering cost per pregnancy. Additionally, improving semen quality has the potential to increase the quality and quantity of semen produced by genetically superior sires, hence promising wide availability of semen from elite sires at a more reasonable price (Butler et al., 2019).

Semen quality traits are routinely recorded at AI centers for production and marketing decisions. Thus, large-scale data on these traits are available and can be an important source of correlated information to improve traditional fertility traits registered in females. Traditional female fertility traits in general tend to have low heritability in different cattle breeds (Berry et al., 2014). Previous studies on genetic parameters of semen quality traits indicate moderate heritability estimates (Berry et al., 2014; Yin et al., 2019; Olsen et al., 2020). Given that pregnancy rate for males is significantly affected by semen quality (DeJarnette et al., 2004) and that it is highly genetically correlated with pregnancy rate in females (Berry et al., 2011), selection for semen quality traits could potentially lead to improvement in pregnancy rate not only for males but also for females (Berry et al., 2014).

Nonetheless, literature on the genetic parameters of semen quality traits is scarce. To our knowledge, no study so far has reported genetic correlations between semen quality measures and service sire NRR. The objectives of this study were to estimate genetic parameters of semen quality traits using large data from routine semen collection in the Nordic Holstein and 
to estimate genetic correlations between semen quality traits and service sire NRR based on insemination records of cows in different parities.

\section{MATERIALS AND METHODS}

\section{Phenotypes}

Data on 100,058 ejaculates that were collected between the years 2006 and 2019 from 2,885 Nordic Holstein bulls were provided by Viking Genetics (Randers, Denmark). All ejaculates were collected at Viking Genetics' semen production sites $(\mathrm{n}=11)$ in Denmark, Sweden, and Finland. Semen quality was assessed by trained laboratory technicians immediately after ejaculate collection or postthaw. The analyzed semen quality traits and number of bulls with records for each of these traits are presented in Table 1. All quality traits were evaluated as described previously in Christensen et al. (2011). Briefly, sperm motility was defined as the percentage of motile spermatozoa and assessed subjectively by an experienced technician using phase contrast microscopy. Sperm viability and concentration were assessed using flow cytometric analyses, where viability was defined as the percentage of live spermatozoa. Live or dead spermatozoa were identified as the ones with intact or ruptured cellular membranes, respectively, upon staining with SYBR-14 and propidium iodide. Concentration was assessed using counting beads as described previously (Christensen et al., 2011). Ejaculate volume was estimated from the weight of the ejaculate using a density of $1.08 \mathrm{~g} / \mathrm{mL}$.

Age of bulls at ejaculate collection ranged between 7 and 160 mo. Figure 1 presents the distribution of phenotypic measurements for the studied trait across the age of bulls at ejaculate collection in months. For the statistical analysis, age at ejaculate collection was categorized into 3 classes: (1) less than 12 mo, (2) between 12 and $15 \mathrm{mo}$, and (3) more than 15 mo. The age intervals chosen for classification are related to the maturation and production status of the bulls, indicating peripubertal (age up to $12 \mathrm{mo}$ ), pubertal (12-15 mo with the most intense production), and mature (older than $15 \mathrm{mo}$ ) bulls.

One of the objectives of this study was to estimate the correlations between semen quality traits and service sire NRR based on NRR at $56 \mathrm{~d}$ after the first insemination. However, NRR data were not available at ejaculate level. Therefore, summary data were instead obtained for a total of 2,142 of the 2,885 bulls on NRR $\mathrm{s}$ within $56 \mathrm{~d}$ after the first insemination of heifers and cows at parities 1,2 , and 3 or more. The NRR data for each bull were collected from insemination of cows across different herds and countries as well as years and seasons. Therefore, the data were corrected to account for effects of herd, year, and season in the country where insemination took place (Denmark, Sweden, or Finland). Nonreturn rate observations from the 3 countries were subsequently combined into weighted average before further analyses. The NRR data were collected and precorrected by the Nordic Cattle Genetic Evaluation center (Denmark). Nonreturn rates were recorded for a bull when the number of inseminations exceeded 100. Number of bulls with NRR data in each class of inseminated cows (i.e., heifer, parity 1-3) and the mean, minimum, and maximum number of inseminations used per bull are presented in Table 2 .

\section{Genotypes}

Bulls were genotyped using the Illumina Infinium BovineSNP50 BeadChip (50k), BovineLD BeadChip (Boichard et al., 2012), or one of the first 4 versions of the EuroG10k SNP chip (Boichard et al., 2018). The EuroG10k SNP chip is composed of 6,909 SNP from BovineLD Genotyping BeadChip v.2 (Boichard et al., 2012) as well as variants from the 50k or HD Illumina chip and 6,079 whole-genome sequence variants

Table 1. Number of individuals $\left(\mathrm{N}_{\text {ind }}\right)$ and records $\left(\mathrm{N}_{\mathrm{obs}}\right)$, phenotypic mean, and coefficients of variation for semen quality traits

\begin{tabular}{lrrrr}
\hline Trait & $\mathrm{N}_{\text {ind }}$ & $\mathrm{N}_{\text {obs }}$ & Mean & $\mathrm{CV}$ \\
\hline Concentration & & & & \\
$\quad$ Precryopreservation $\left(10^{9} \mathrm{sperm} / \mathrm{mL}\right)$ & 2,702 & 89,857 & 1.29 & 0.44 \\
$\quad$ Postcryopreservation $\left(10^{6} \mathrm{sperm} / \mathrm{mL}\right)$ & 2,256 & 66,917 & 60.80 & 0.22 \\
$\quad$ Volume $(\mathrm{mL})$ & 2,710 & 92,334 & 4.98 & 0.49 \\
Motility (\%) & & & & \\
$\quad$ Precryopreservation & 828 & 17,328 & 69.17 & 0.18 \\
$\quad$ Postcryopreservation & 2,712 & 77,148 & 54.62 & 0.16 \\
$\quad$ Viability (\%) & 2,274 & 80,438 & 82.91 & 0.13 \\
$\quad$ Precryopreservation & 2,240 & 66,428 & 59.16 & 0.16 \\
$\quad$ Postcryopreservation & 1,933 & 42,509 & 435.34 & 0.81 \\
Doses (no./ejaculate) & & & & \\
\hline
\end{tabular}


(Boichard et al., 2018). The whole-genome variants were selected as peaks of QTL detected from imputed whole-genome sequence data across different European breeds, functional annotations and linkage disequilibrium between SNP, and so on (Brøndum et al., 2015; Boichard et al., 2018).
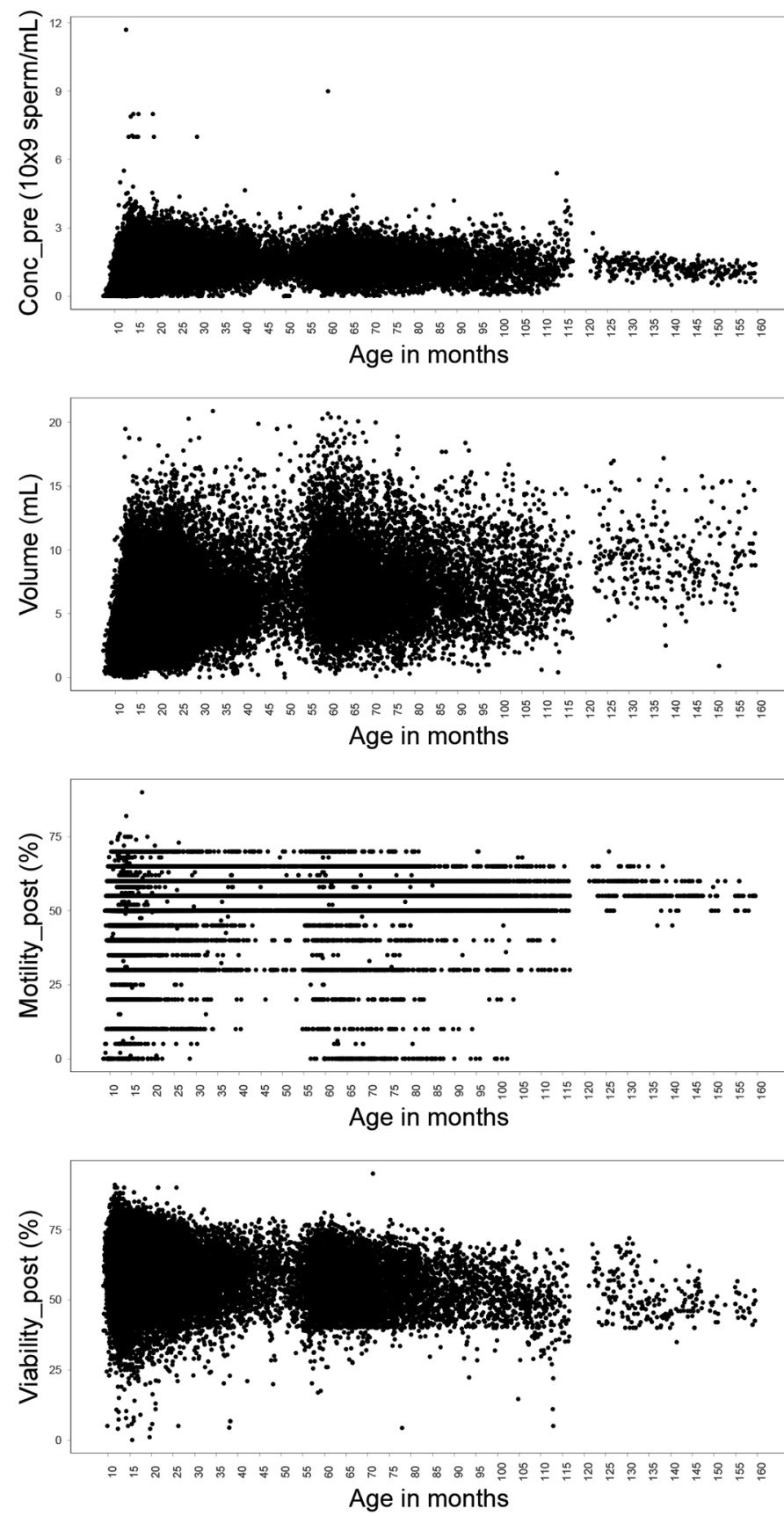

Genotype data were subjected to quality control steps, including removing variants with a minor allele frequency of less than 0.01 as well as variants with Hardy-Weinberg equilibrium $P$-value less than $1 \times$ $10^{-7}$. Additionally, markers with a call rate below $85 \%$ were excluded. Ultimately, 41,546 SNP were available
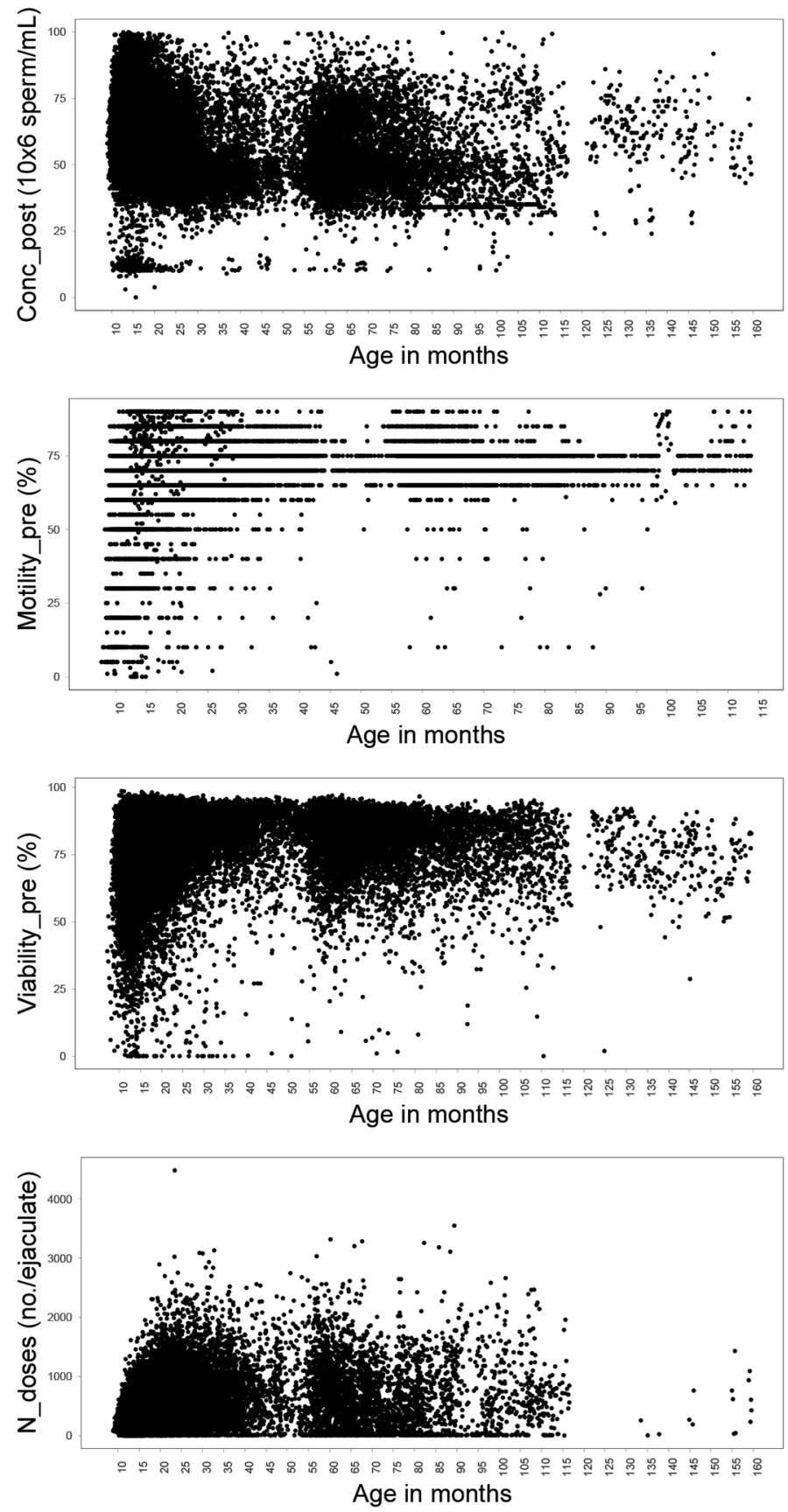

Figure 1. Plots of phenotypic measurements in semen quality traits against age of bulls in months at ejaculate collection. Conc = concentration; Pre = precryopreservation; post = postcryopreservation; N_doses = number of doses per ejaculate. 
Table 2. Number of individuals $\left(\mathrm{N}_{\text {ind }}\right)$ and mean number of inseminations recorded per individual for nonreturn rate (NRR) in different parity of inseminated cows and heifers

\begin{tabular}{lrcrc}
\hline & & \multicolumn{3}{c}{ Records (no./individual) } \\
\cline { 3 - 5 } Trait & $\mathrm{N}_{\text {ind }}$ & Minimum & Mean & Maximum \\
\hline NRR heifers & 832 & 100 & 1,778 & 86,283 \\
NRR parity1 & 2,095 & 100 & 699 & 27,843 \\
NRR parity2 & 990 & 100 & 1,021 & 32,382 \\
NRR parity3 & 508 & 100 & 1,072 & 17,176 \\
\hline
\end{tabular}

for the genetic analyses. Map positions were based on the UMD 3.1 reference assembly (Zimin et al., 2009).

\section{Statistical Analysis}

The REML approach in DMU was used to estimate variance components and genetic parameters (Madsen and Jensen, 2013). The statistical model to describe observations of semen quality traits is

$$
\mathbf{y}=\mathbf{X} \boldsymbol{\beta}+\mathbf{Z}_{1} \mathbf{g}+\mathbf{Z}_{2} \mathbf{c}+\mathbf{e},
$$

where $\mathbf{y}$ is the vector of phenotypes, $\boldsymbol{\beta}$ is the vector of fixed effects [i.e., age class (1-3), production site (1-11), and month and year of ejaculate collection], $\mathbf{X}$ is the incidence matrix relating observations with fixed effects, $\mathbf{g}$ is the vector of random additive genetic effects, $\mathbf{Z}_{1}$ is the incidence matrix relating observations with random genetic effects, $\mathbf{c}$ is the vector of permanent environmental effects, $\mathbf{Z}_{2}$ is the incidence matrix relating observations with permanent environmental effects, and $\mathbf{e}$ is the vector of residual effects. The random effects are assumed to be normally distributed. Thus, $\mathbf{g} \sim N\left(0, \mathbf{G} \sigma_{\mathrm{g}}^{2}\right)$, where $\mathbf{G}$ is a genomic relationship matrix and $\sigma_{\mathrm{g}}^{2}$ is the additive genetic variance; c $\sim N\left(0, \mathbf{I} \sigma_{\mathrm{c}}^{2}\right)$, where $\mathbf{I}$ is an identity matrix of dimension equal to the number of individuals with records and $\sigma_{\mathrm{c}}^{2}$ is the permanent environmental variance; and $\mathbf{e} \sim N\left(0, \mathbf{I} \sigma_{\mathrm{e}}^{2}\right)$, where $\mathbf{I}$ is an identity matrix of dimension equal to the number of records and $\sigma_{\mathrm{e}}^{2}$ is the residual variance.

Univariate analyses were performed to estimate the heritability $\left(\mathrm{h}^{2}\right)$, which was defined as

$$
\mathrm{h}^{2}=\frac{\sigma_{\mathrm{g}}^{2}}{\sigma_{\mathrm{g}}^{2}+\sigma_{\mathrm{c}}^{2}+\sigma_{\mathrm{e}}^{2}} .
$$

Repeatability $(\mathrm{t})$ was defined as

$$
\mathrm{t}=\frac{\sigma_{\mathrm{g}}^{2}+\sigma_{\mathrm{c}}^{2}}{\sigma_{\mathrm{g}}^{2}+\sigma_{\mathrm{c}}^{2}+\sigma_{\mathrm{e}}^{2}} .
$$

Bivariate analyses were implemented to estimate correlations between the semen quality traits using Equation 1.

Correlations between the semen quality traits and NRR were estimated using weighted bivariate analyses with corrected summary phenotypes. For the semen quality traits, the summary phenotypes were calculated by summing all the random effects predicted using Equation 1 for each bull, including the average residual effect. The summary phenotypes for NRR were described above. The bivariate model, including corrected phenotypes for one of the NRR traits (NRR within 56 $\mathrm{d}$ after the first insemination of heifers and cows at parities 1, 2, and 3 or more) and corrected phenotypes for one of the semen quality traits, is implemented as follows:

$$
\mathbf{y}=1 \mu+\mathbf{Z g}+\mathbf{e},
$$

where $\mathbf{y}$ is the vector of corrected phenotypes, $\mathbf{1}$ is the vector of ones, $\mu$ is the overall mean, $g$ is the vector of random genetic effects, $\mathbf{Z}$ is the incidence matrix relating observations with random genetic effects, and $\mathbf{e}$ is the vector of residual effects. For the residuals, $\mathbf{e} \sim N\left(0, \mathbf{D} \sigma_{\mathrm{e}}^{2}\right)$, where $\mathbf{D}$ is a diagonal matrix with elements $d_{i j}=\frac{1-r_{Y c}^{2}}{r_{Y c}^{2}}$ for each bull $i$ for trait $j$ in the bivariate analysis to account for heterogeneous residual variances due to different reliabilities of corrected phenotypes $\left(\mathrm{r}_{\mathrm{Yc}}^{2}\right)$ as a result of differences between bulls in the number of records used to calculate the corrected phenotypes for the respective trait. Reliabilities of the corrected phenotypes $\left(\mathrm{r}_{\mathrm{Yc}}^{2}\right)$ were calculated for each bull as

$$
\mathrm{r}_{\mathrm{Yc}}^{2}=\frac{\mathrm{N}_{\mathrm{i}}}{\mathrm{N}_{\mathrm{i}}+\lambda},
$$

where $\mathrm{N}_{\mathrm{i}}$ is the number of observations available for bull i for each trait in the bivariate analysis (i.e., the number of records for the semen quality trait or the number of inseminations with NRR outcomes recorded 
for each bull). Lambda was the ratio of residual to bull variances calculated as $\lambda=\frac{1-\mathrm{h}^{2}}{\mathrm{~h}^{2}}$ and was calculated separately for each trait in the bivariate analysis using heritability values estimated as described in Equation 2 for the semen quality traits, whereas heritability for the NRR trait was approximated in a step-wise procedure based on the following single-trait analysis:

$$
\mathbf{y}=\mathbf{1} \mu+\mathbf{Z g}+\mathbf{e},
$$

where $\mathbf{y}$ is the vector of summary NRR data for each bull based on insemination to cows; 1 is the vector of ones, $\mu$ is the overall mean; $\mathbf{e}$ is the vector of residual effects assumed to be normally distributed: $\mathbf{e} \sim N\left(0, \mathbf{D} \sigma_{\mathrm{e}}^{2}\right)$, where $\mathbf{D}$ is a diagonal matrix with elements $d_{i j}=\frac{1}{W}$, where $W$ is the number of inseminations for each bull standardized to have a mean value of 1 ; and $\mathbf{Z}$ and $\mathbf{g}$ are as described for Equation 4. The heritability estimated using Equation 6 based on the summary NRR data was then transformed to an approximate individual insemination-level heritability by assuming that the heritability based on the summary data is the average reliability of the summary data given the mean number of insemination used to derive the summary data as

$$
\mathrm{r}_{\mathrm{NRRsummary}}^{2}=\mathrm{h}_{\mathrm{NRR} \text { summary }}^{2}=\frac{\mathrm{N}_{\mathrm{o}}}{\mathrm{N}_{\mathrm{o}}+\lambda},
$$

where $\mathrm{N}_{\mathrm{o}}$ is the mean number of inseminations per bull. Thus,

$$
\lambda=\frac{\mathrm{N}_{\mathrm{o}}}{\mathrm{h}_{\text {NRRsummary }}^{2}}-\mathrm{N}_{\mathrm{o}},
$$

which was then used to approximate the individual insemination-level heritability and subsequently the reliabilities and weights of NRR for each bull.

\section{RESULTS}

\section{Descriptive Statistics}

Table 1 presents the phenotypic mean and coefficients of variation for the semen quality traits studied. The bulls had an average ejaculate volume of $4.98 \mathrm{~mL}$, precryopreservation sperm concentration of $1.29 \times 10^{9} /$ $\mathrm{mL}$, sperm motility of $69.17 \%$, and sperm viability of
$82.91 \%$. A high coefficient of variability was observed between the records for the number of doses per ejaculate $(\mathrm{CV}=0.81)$, followed by ejaculate volume $(\mathrm{CV}=$ $0.49)$ and semen concentration $(\mathrm{CV}=0.44)$. Phenotypic measurements for the studied semen quality traits appeared to vary across the age of bulls at ejaculate collection (Figure 1). Generally, across the traits, measurements from bulls in early ages $(<15 \mathrm{mo})$ appear to be highly dispersed between the minimum and maximum observed values for the respective trait and tend to stabilize as age increases. This is best reflected in Figure 1 for precryopreservation sperm viability and sperm concentration as well as ejaculate volume. Figure 2 presents box plots of phenotypic values for the semen quality traits in the 3 age classes. Generally, higher phenotypic values were observed for most of the semen qualities, except motility post- and precryopreservation, in the third age class $(>15$ mo of age at semen collection), followed by the second age group.

\section{Heritability and Repeatability of Semen Quality Traits}

Estimates of phenotypic variance, heritability, and repeatability in the semen quality traits are presented in Table 3. Heritability estimates in the semen quality traits were generally low to moderate $(0.06-0.45)$, whereas repeatability estimates were generally moderate to high (0.35-0.61). Number of doses per ejaculate had the highest heritability and repeatability estimates, whereas the estimates for postcryopreservation sperm concentration were the lowest. Comparing between the pre- and postcryopreservation measurements of the same quality indicator, sperm viability had similar heritability in both pre- and postcryopreservation, whereas heritability for precryopreservation sperm motility was more than twice that of postcryopreservation sperm motility.

\section{Genetic and Phenotypic Correlations Among the Semen Quality Traits}

Table 4 presents genetic (above diagonal) and phenotypic (below diagonal) correlations among the semen quality traits. High positive genetic and phenotypic correlations were observed between pre- and postcryopreservation sperm viability $\left(r_{g}^{2}=0.93 ; r_{p}^{2}=0.76\right)$ in contrast to sperm motility, which had relatively low genetic correlation between the pre- and postcryopreservation measurements $\left(r_{g}^{2}=0.26 ; r_{p}^{2}=0.19\right)$. Postcryopreservation sperm motility showed strong positive genetic correlations with both precryopreservation 

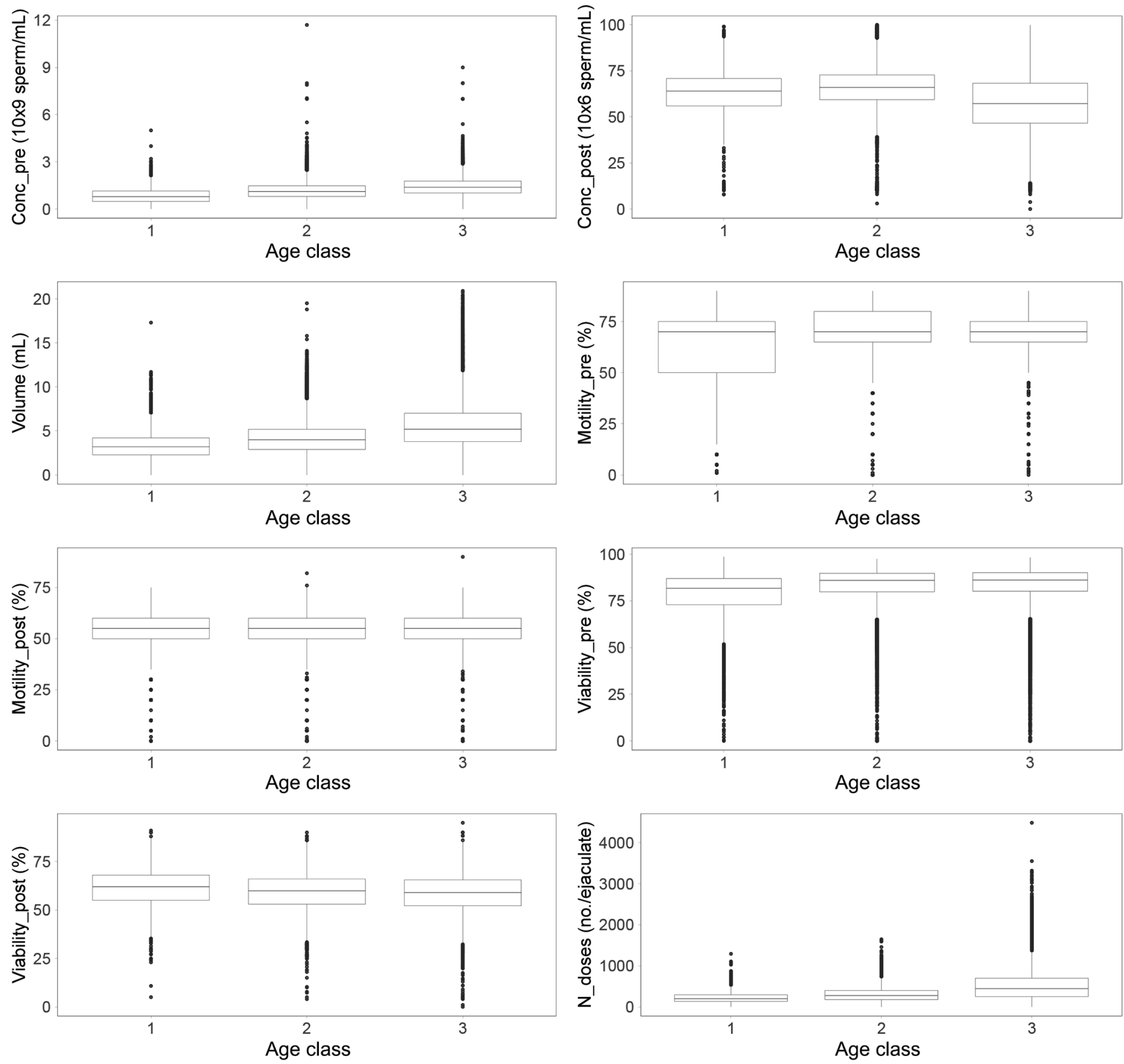

Figure 2. Box plots showing phenotypic means per age class for the studied semen quality traits. Conc $=$ concentration; Pre $=$ precryopreservation; post $=$ postcryopreservation; N_doses $=$ number of doses per ejaculate. The top and bottom of the boxes represent the upper and lower quartile, respectively; the horizontal line inside the box represents the median; whiskers indicate variability outside the upper and lower quartiles, and the dots along the whiskers indicate outlier records.

$\left(r_{g}^{2}=0.86\right)$ and postcryopreservation $\left(r_{g}^{2}=0.82\right)$ sperm viability. Ejaculate volume showed moderate negative genetic correlations with precryopreservation $\left(r_{g}^{2}=-0.53\right)$ and postcryopreservation $\left(r_{g}^{2}=-0.54\right)$ sperm viability. Number of doses per ejaculate had moderate to high positive genetic correlations with precryopreservation sperm motility $\left(r_{g}^{2}=0.53\right)$ and ejaculate volume $\left(r_{g}^{2}=0.94\right)$ and moderate negative 
genetic correlations with sperm viability precryopreservation $\left(r_{g}^{2}=-0.52\right)$ and postcryopreservation $\left(r_{g}^{2}=-0.55\right)$.

\section{Genetic and Phenotypic Correlations Between Semen Quality Traits and NRR}

Table 5 presents genetic and phenotypic correlations between semen quality traits and service sire NRR traits according to parity of inseminated cows and heifers. Generally, the estimates of correlations between the semen quality traits and NRR varied between parities of inseminated cows and heifers. Compared with the other semen quality traits, postcryopreservation sperm motility $\quad\left(r_{g}^{2}=0.45-0.67 ; r_{p}^{2}=0.41-0.59\right), \quad$ precryopreservation sperm viability $\left(r_{g}^{2}=0.21-0.42 ; r_{p}^{2}=0.21-0.32\right), \quad$ postcryopreservation sperm viability $\left(r_{g}^{2}=0.17-0.31 ; r_{p}^{2}=0.17-0.23\right)$, and precryopreservation sperm concentration $\left(r_{g}^{2}=0.11-0.22 ; r_{p}^{2}=0.11-0.22\right)$ showed relatively higher genetic and phenotypic correlations across the NRR traits defined. For most of these traits shown to have moderate to high correlation with the NRR traits, the genetic and phenotypic correlations estimated based on insemination to cows in parity 3 or more were relatively higher than those estimated based on insemination of heifers and cows in parities 1 and 2. Accordingly, the highest genetic and phenotypic correlations were the ones of postcryopreservation sperm motility $\left(r_{g}^{2}=0.67 ; r_{p}^{2}=0.59\right)$ and precryopreservation sperm viability $\left(r_{g}^{2}=0.42 ; r_{p}^{2}=0.32\right)$ with the NRR based on insemination of cows at parity 3 .

\section{DISCUSSION}

\section{Phenotypic Trends and Genetic Parameters of Semen Quality Traits}

The current study was based on a data set with 100,058 ejaculates from 2,858 bulls, which was one of the largest data sets used in the genetic parameter estimation of semen quality traits in the literature. Our study indicates that measurements in semen quality traits from bulls at an early age might be highly unstable compared with measurements at later ages and that semen quality measurements tend to be higher with a bull's maturation. Bull age at ejaculate collection is known to affect semen characteristics (Mathevon et al., 1998); higher semen volume and quality were generally observed in mature bulls compared with younger ones (Fuerst-Waltl et al., 2006; Olsen et al., 2020).

Generally, the heritability values estimated for the Nordic Holstein bulls in this study were within the range of heritability estimates reported for semen quality traits in the literature (e.g., Mathevon et al., 1998; Berry et al., 2014; Olsen et al., 2020). Our results indicated generally low to moderate heritability estimates for the semen quality traits, ranging from 0.06 (sperm concentration postcryopreservation) to 0.45 (number of doses per ejaculate).

The lowest heritability estimate was reported for postcryopreservation sperm concentration. Postcryopreservation sperm concentration had also low genetic correlation with precryopreservation sperm concentration. Semen doses are diluted based on observations of other precryopreservation quality indicators, such as sperm viability and ejaculate volume. Therefore, management decisions underlie most of the variation in sperm concentration postcryopreservation rather than bull genetics; therefore, the observed low heritability in this trait is not unexpected.

Table 3. Phenotypic variance $\left(\sigma_{\mathrm{p}}^{2}\right)$, heritability $\left(\mathrm{h}^{2} ; \mathrm{SE}\right.$ in parentheses), and repeatability ( $\mathrm{t}$; SE in parentheses) for semen quality traits

\begin{tabular}{lrrr}
\hline Trait & \multicolumn{1}{c}{$\sigma_{\mathrm{p}}^{2}$} & $\mathrm{~h}^{2}$ & $\mathrm{t}$ \\
\hline Concentration & & & \\
$\quad$ Precryopreservation $\left(10^{9} \mathrm{sperm} / \mathrm{mL}\right)$ & 0.28 & $0.11(0.01)$ & $0.36(0.01)$ \\
$\quad$ Postcryopreservation $\left(10^{6} \mathrm{sperm} / \mathrm{mL}\right)$ & 7.65 & $0.06(0.01)$ & $0.25(0.01)$ \\
Volume (mL) & & $0.39(0.02)$ & $0.59(0.01)$ \\
Motility (\%) & 162.30 & $0.32(0.04)$ & $0.50(0.04)$ \\
$\quad$ Precryopreservation & 82.25 & $0.13(0.02)$ & $0.39(0.01)$ \\
$\quad$ Postcryopreservation & & & \\
Viability & 111.06 & $0.18(0.02)$ & $0.44(0.01)$ \\
$\quad$ Precryopreservation (\%) & 74.39 & $0.17(0.02)$ & $0.41(0.01)$ \\
$\quad$ Postcryopreservation (\%) & $179,726.60$ & $0.45(0.02)$ & $0.61(0.02)$ \\
Doses (no./ejaculate) & & &
\end{tabular}


Gebreyesus et al.: GENETIC PARAMETERS OF SEMEN QUALITY AND MALE FERTILITY TRAITS
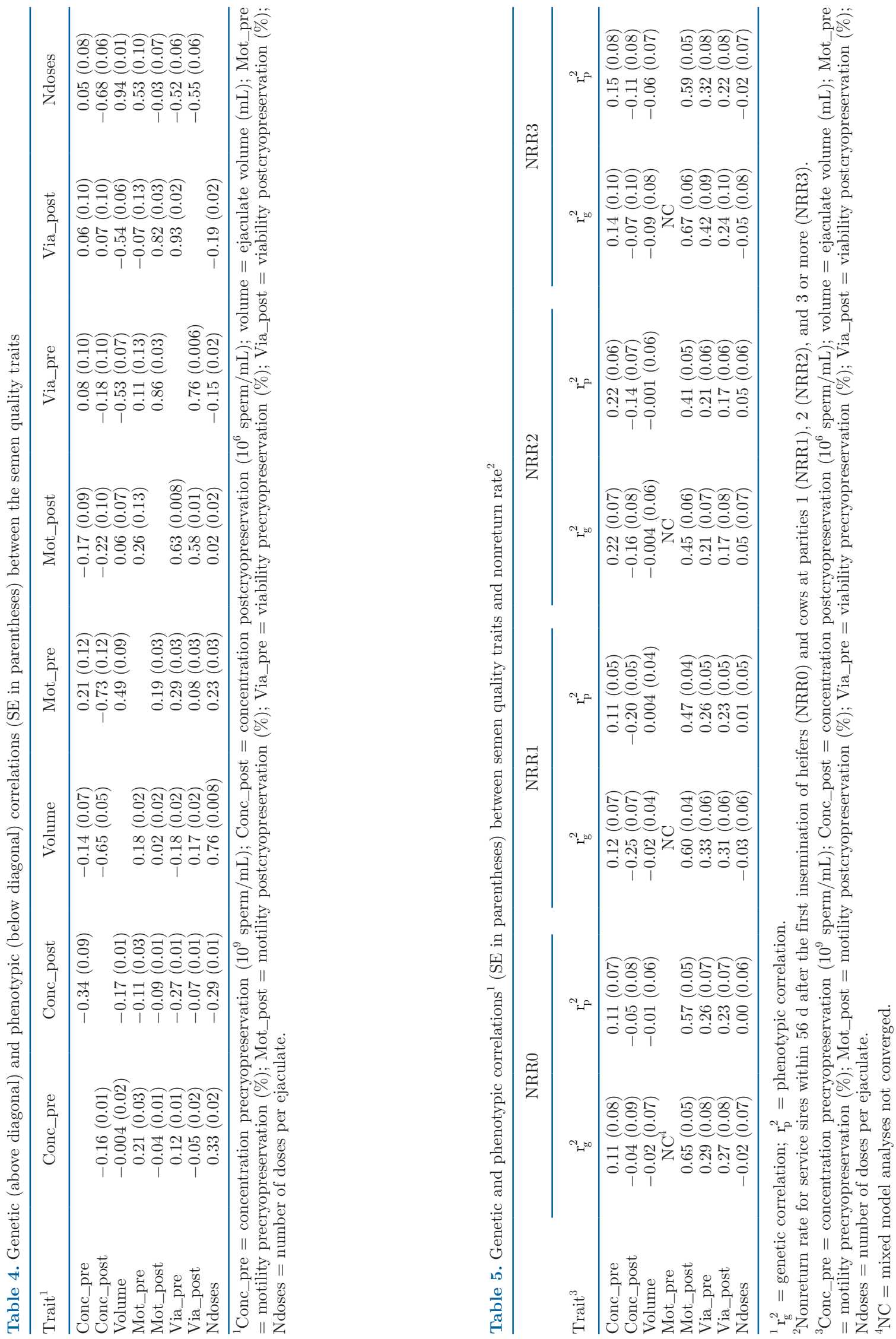
The relatively lower heritability estimate reported in this study for fresh semen sperm concentration was comparable with the pooled mean heritability estimate reported by Berry et al. (2014) based on a meta-analysis of results from 28 different studies or populations. Our heritability estimate for fresh ejaculate volume in the Nordic Holstein was also comparable with estimates reported by Mathevon et al. (1998) in Canadian Holstein bulls but higher than estimates reported in Chinese Holstein (Yin et al., 2019), Norwegian Red (Olsen et al., 2020), and US Hereford (Kealey et al., 2006) bulls.

Heritability estimates for motility precryopreservation in this study were among the high estimates in the literature and substantially higher than the pooled mean heritability estimate of 0.054 reported by the meta-analysis study of Berry et al. (2014). The genetic correlation between sperm motility pre- and postcryopreservation was quite low despite our expectation of moderate to high estimates. To our knowledge, no studies have reported the genetic correlation between preand postcryopreservation sperm motility with which we could compare our findings. Given the relatively higher standard error of the correlation estimate, the estimate could be less reliable due to the relatively small data set for precryopreservation mortality as few of the bulls $(29 \%)$ have records for this trait. At Viking Genetics AI centers located in Denmark, which account for the majority of semen production, routine evaluation for motility precryopreservation started in 2018. This trait is not routinely evaluated for across all ejaculates, thus limiting the data available for this study. Therefore, all parameter estimates reported for motility precryopreservation in this study should be interpreted cautiously due to the relatively low sample size used in the analyses.

The highest heritability value was estimated for the number of doses per ejaculate followed by ejaculate volume. A very high genetic correlation (0.94) was found between these 2 traits, indicating that ejaculate volume underlies much of the variation in the number of doses possible to produce per ejaculate.

\section{Predictive Value of the Semen Quality Traits for Service Sire NRR}

Our study reports genetic correlations between semen quality traits and service sire NRR using relatively large data sets. The results showed moderate to high genetic and phenotypic correlations between NRR and some of the semen quality traits, including sperm viability pre- and postcryopreservation, motility postcryopreservation, and precryopreservation sperm concentration. The current study confirms a previous report based on analysis of phenotypic correlations by Christensen et al. (2011), which suggested promising predictive abilities of pre- and postcryopreservation sperm viability as well as precryopreservation semen concentration for NRR at $56 \mathrm{~d}$ post-AI. Our findings of genetic and phenotypic correlation analysis indicate that, in addition to those traits suggested by Christensen et al. (2011), postcryopreservation sperm motility might have promising predictive ability for service sire NRR at $56 \mathrm{~d}$ post-AI. Similarly, a phenotypic level study using crossbred Indonesian bulls showed significant relationships between male fertility measured as conception rate and postcryopreservation sperm viability and motility (Pardede et al., 2020). Moreover, because ejaculates with low semen quality measures are not used for insemination, the NRR data are left-censored in relation to the semen quality traits, and hence the genetic and phenotypic correlation estimates in this study might underestimate the true correlations between these traits. Our results also indicate that genetic and phenotypic correlations between the semen quality traits and service sire NRR are affected by parity of inseminated cows, with a trend of higher genetic correlations between some of the semen quality traits and NRR for bulls based on insemination to cows in parity 3 .

To our knowledge, this is the first time that genetic correlations between the semen quality traits and service sire NRR have been reported. Due to the current limitations on the ability to capture NRR data at the ejaculate level, our study used summary data based on a varying number of records per bull, which might affect the correlation results given potential variations in NRR between ejaculates from the same bull.

\section{CONCLUSIONS}

Based on a large data set of 100,058 ejaculates from 2,858 Nordic Holstein bulls, this study reports low to moderate heritability and moderate to high repeatability estimates for semen quality traits, including pre- and postcryopreservation semen concentration, sperm motility, sperm viability, ejaculate volume, and number of doses per ejaculate. These results indicate the possibility of implementing selective breeding to improve semen quality traits in the Nordic Holstein. Additionally, our study found moderate to high genetic and phenotypic correlations between NRR and some of the semen quality traits. The results indicate that some of the semen quality traits, specifically pre- and postcryopreservation sperm viability, postcryopreservation sperm motility, and precryopreservation sperm concentration, can be useful predictors for service sire NRR. Positive and strong genetic correlations between 
these semen quality traits and service sire NRR also indicate that selection for the semen quality traits might be favorable for improving service sire NRR.

\section{ACKNOWLEDGMENTS}

This work was supported by the EliteSemen project funded by the Milk Levy Foundation (Denmark). The authors declare that they have no conflicts of interest.

\section{REFERENCES}

Berry, D. P., B. Eivers, G. Dunne, and S. McParland. 2019. Genetics of bull semen characteristics in a multi-breed cattle population. Theriogenology 123:202-208. https://doi.org/10.1016/j.theriogenology .2018.10.006.

Berry, D. P., R. D. Evans, and S. McParland. 2011. Evaluation of bull fertility in dairy and beef cattle using cow field data. Theriogenology $75: 172-181$.

Berry, D. P., E. Wall, and J. E. Pryce. 2014. Genetics and genomics of reproductive performance in dairy and beef cattle. Animal 8(Suppl. 1):105-121. https://doi.org/10.1017/S1751731114000743.

Boichard, D., M. Boussaha, A. Capitan, D. Rocha, C. Hozé, M. P. Sanchez, T. Tribout, R. Letaief, P. Croiseau, C. Grohs, W. Li, C. Harland, C. Charlier, M. S. Lund, G. Sahana, M. Georges, S. Barbier, W. Coppieters, S. Fritz, and B. Guldbrandtsen. 2018. Experience from large scale use of the EuroGenomics custom SNP chip in cattle. Page 675 in 11th World Congress of Genetics Applied to Livestock Production, Auckland, New Zealand.

Boichard, D., H. Chung, R. Dassonneville, X. David, A. Eggen, S. Fritz, K. J. Gietzen, B. J. Hayes, C. T. Lawley, T. S. Sonstegard, C. P. Van Tassell, P. M. VanRaden, K. A. Viaud-Martinez, G. R. Wiggans, and Bovine LD Consortium. 2012. Design of a bovine low-density SNP array optimized for imputation. PLoS One 7:e34130. https://doi.org/10.1371/journal.pone.0034130.

Brøndum, R. F., G. Su, L. Janss, G. Sahana, B. Guldbrandtsen, D. Boichard, and M. S. Lund. 2015. Quantitative trait loci markers derived from whole genome sequence data increases the reliability of genomic prediction. J. Dairy Sci. 98:4107-4116. https://doi.org/ 10.3168/jds.2014-9005.

Butler, M. L., J. M. Bormann, R. L. Weaber, D. M. Grieger, and M. M. Rolf. 2019. Selection for bull fertility: A review. Transl. Anim. Sci. 4:423-441. https://doi.org/10.1093/tas/txz174.
Christensen, P., R. Labouriau, A. Birck, G. B. Boe-Hansen, J. Pedersen, and S. Borchersen. 2011. Relationship among seminal quality measures and field fertility of young dairy bulls using low-dose inseminations. J. Dairy Sci. 94:1744-1754. https://doi.org/10.3168/ jds.2010-3087.

DeJarnette, J. M., C. E. Marshal, R. W. Lenz, D. R. Monke, W. H. Ayars, and C. G. Sattler. 2004. Sustaining the fertility of artificially inseminated dairy cattle: The role of the artificial insemination industry. J. Dairy Sci. 87(E-Suppl.):93-104. https://doi.org/ 10.3168/jds.S0022-0302(04)70065-X.

Fuerst-Waltl, B., H. Schwarzenbacher, C. Perner, and J. Sölkner. 2006. Effects of age and environmental factors on semen production and semen quality of Austrian Simmental bulls. Anim. Reprod. Sci. 95:27-37.

Kealey, C. G., M. D. MacNeil, M. W. Tess, T. W. Geary, and R. A. Bellows. 2006. Genetic parameter estimates for scrotal circumference and semen characteristics of line 1 Hereford bulls. J. Anim. Sci. 84:283-290.

Madsen, P., and J. Jensen. 2013. A User's Guide to DMU. Version 6, release 5.2. Aarhus University.

Mathevon, M., M. M. Buhr, and J. C. M. Dekkers. 1998. Environmental, management, and genetic factors affecting semen production in Holstein bulls. J. Dairy Sci. 81:3321-3330.

Morrell, J. M., A. S. Valeanu, N. Lundeheim, and A. Johannisson. 2018. Sperm quality in frozen beef and dairy bull semen. Acta Vet. Scand. 60:41. https://doi.org/10.1186/s13028-018-0396-2.

Olsen, H. B., B. Heringstad, and G. Klemetsdal. 2020. Genetic analysis of semen characteristic traits in young Norwegian Red bulls. J. Dairy Sci. 103:545-555. https://doi.org/10.3168/jds.2019-17291.

Pardede, B. P., M. Agil, Y. Yudi, and I. Supriatna. 2020. Relationship of frozen-thawed semen quality with the fertility rate after being distributed in the Brahman Cross Breeding Program. Vet. World 13:2649-2657. https://doi.org/10.14202/vetworld.2020.2649-2657.

Yin, H., L. Fang, C. Qin, and S. Zhang. 2019. Estimation of the genetic parameters for semen traits in Chinese Holstein bulls. BMC Genet. 20. https://doi.org/10.1186/s12863-019-0752-x.

Zimin, A. V., A. L. Delcher, L. Florea, D. R. Kelley, M. C. Schatz, D. Puiu, F. Hanrahan, G. Pertea, C. P. Van Tassell, T. S. Sonstegard, G. Marçais, M. Roberts, P. Subramanian, J. A. Yorke, and S. L. Salzberg. 2009. A whole-genome assembly of the domestic cow, Bos taurus. Genome Biol. 10:R42.

\section{ORCIDS}

Grum Gebreyesus @ https://orcid.org/0000-0003-4757-3060 